Research Article

\title{
Source Term Estimation under the SBLOCA-Induced Severe Accident Condition in the SMART
}

\author{
Jaehyun Ham (D), Sang Ho Kim, Sung Il Kim, Byeonghee Lee, Jong-Hwa Park, \\ Rae-Joon Park, and Jaehoon Jung \\ Korea Atomic Energy Research Institute, 1045 Daedeok-daero, Yuseong-Gu, Daejeon 34039, Republic of Korea \\ Correspondence should be addressed to Jaehyun Ham; jhham@kaeri.re.kr
}

Received 6 November 2020; Revised 21 March 2021; Accepted 31 March 2021; Published 13 April 2021

Academic Editor: Sheng Fang

Copyright ( 2021 Jaehyun Ham et al. This is an open access article distributed under the Creative Commons Attribution License, which permits unrestricted use, distribution, and reproduction in any medium, provided the original work is properly cited.

\begin{abstract}
The SMART is a system-integrated modular reactor in which a nuclear steam supply system with a thermal power of $365 \mathrm{MW}$ is contained inside of the reactor vessel. Although the probability is very low, the reactor core can be damaged during a small break loss-of-coolant accident when both the passive safety injection system and the passive residual heat removal system are completely unavailable. In this work, a total of five cases were analyzed considering the reactor vessel condition and the availability of the radioactivity removal tanks and the ancillary containment spray system as containment condition variables using MELCOR code. It was estimated that there is no containment failure based on pressure, hydrogen mole fraction, and ablation depth, so that the release fractions of the 12 classes of fission products in MELCOR were evaluated considering design leak only for all cases. The overall source term of the case in which the integrity of the reactor vessel is maintained by the early initiation of the cavity flooding system was similar to that of the reactor vessel failure case. While the release fraction of cesium to the environment was analyzed to increase when there is no water in the radioactivity removal tanks, the fraction is small enough at which the radioactivity of the released cesium-137 remains well below $100 \mathrm{TBq}$, a regulatory limit. Moreover, it was found that the source term can be cut in half if the ancillary containment spray system is available. The results of this study verify the safety performance of the SMART under the small break loss-of-coolant severe accident condition with respect to the source term of interest.
\end{abstract}

\section{Introduction}

Increasing interest and demand for small modular reactors is driving related practical achievements such as design completion, design certification, and construction. Various types of such reactors have been proposed globally, typically classified according to the type of coolant. Among them, light water-cooled reactors are at the forefront of technology, like conventional large nuclear power plants.

CAREM-25 (Central Argentina de Elementos Modulares) was designed to deliver $27 \mathrm{MW}$ of electrical power with minimum operator feedback control [1]. A CAREM-25 prototype is currently being built by CNEA (Argentine National Atomic Energy Commission) at a site next to the Atucha nuclear power station in Lima, Argentina [2]. China has developed various types of small modular reactors such as the ACPR (Advanced Customer-friendly Practicable
Reliable) series including the ACPR100 for onshore $140 \mathrm{MW}$ plants and the ACPR50S for offshore $60 \mathrm{MW}$ plants of electrical power [2]. The barge-mounted KLT-40S reactor developed by the Russian Federation has already received design approval from the Russian regulatory authority. NuScale, developed by NuScale Power, LLC, is a modular plant designed in the US with 12 reactor modules in a single plant [3] and $160 \mathrm{MW}$ of thermal power per module. The NuScale plant received design certification approval from the US Nuclear Regulatory Commission in August 2020. As a first-of-its-kind project, the first NuScale plant is currently under construction in eastern Idaho and is scheduled to come online in 2029.

In the Republic of Korea, some plant models based on the SMART (System-integrated Modular Advanced ReacTor) design have been developed. The standard design approval for the first SMART, with a thermal power of 
330 MW, was issued by the Nuclear Safety and Security Commission in Korea in July 2012, representing the first license for an integral reactor in the world. Since then, the 365 MW SMART has been developed with fully passive safety systems, with licensing in preparation.

In the reactor vessel (RV) of the SMART, eight helical steam generators and four reactor coolant pumps are integrated and installed, as shown in Figure 1(a). The thermal energy of the superheated steam generated in the core is transferred to the water in the secondary circuit through once-through steam generator tubes. The canned-motor type reactor coolant pumps are horizontally mounted. On the RV, there is no penetration tube or nozzle larger than 2 in. The reactor containment and auxiliary buildings are combined into one arched roof rectangular containment building, as shown in Figure 1(b). In Section 2, the designs and operations of the systems installed as part of the reactor coolant system and containment are explained in more detail with the modeled control volumes and junctions.

The possibility of a large break loss-of-coolant accident (LOCA) like in general pressurized water reactors is fundamentally excluded because, in the SMART, the main components are embedded in the RV without pipe lines. In addition, the reactor includes several design features to enhance safety such as the passive safety injection system (PSIS) and the passive residual heat removal system (PRHRS), both passive features with which the reactor core and the containment can be protected even under station blackout accident conditions.

While the large break LOCA can be excluded owing to the $\mathrm{RV}$ design, there is still a possibility for a small break LOCA (SBLOCA) from a break at the PSIS pipes. Among the possible initiating events, SBLOCA is one of the most conservative accidents (other than containment bypass accidents) in the SMART because the whole volume of gas in the RV can be released following this accident. If the PRHRS and the PSIS are completely unavailable during a SBLOCA, the reactor core can be damaged [4]. Even though this scenario is not likely to occur, it is important to estimate the source terms under this condition to verify safety performance. In particular, the release of cesium (Cs) must be analyzed because of the regulatory rule dictating that the sum of the accident frequencies that can cause a release of Cs-137 exceeding $100 \mathrm{TBq}$ should be less than $1.0 E-6 /$ ry [5].

To estimate source terms in severe accident conditions, integral codes such as MELCOR (Methods for Estimation of Leakages and Consequences Of Releases) or MAAP (Modular Accident Analysis Program) can be used for analysis [6]. Among these, MELCOR is a fully integrated, engineering-level computer code with a modeling capability of the severe accident progression in light-water reactor nuclear power plants. This code is being developed at Sandia National Laboratories for the US Nuclear Regulatory Commission as a second-generation plant risk assessment tool, as is the successor to the source term code package. MELCOR treats a broad spectrum of severe accident phenomena in pressurized water reactors in a unified framework and also includes the estimation of severe accident source terms $[7,8]$.
In this study, source term estimation in a severe accident condition induced by a SBLOCA in the SMART was performed using MELCOR code version 2.2. The status of the containment according to the RV condition and the availabilities of the radioactivity removal tanks (RRTs) and the ancillary containment spray system (ACSS) were estimated based on the resulting pressure, hydrogen mole fraction, and ablation depth. As a final result, the release fractions of fission products to the environment were obtained for the source term.

\section{Analysis Method}

2.1. Source Term Estimation. The fission product analysis model in MELCOR, the RadioNuclide (RN) package, can calculate the release and transport behavior of fission product vapors and aerosols. This fission product model operates on the basis of material classes, which are groups of elements that have similar chemical properties such as volatility. Release of fission product classes can occur via fuel-cladding gaps following the exceedance of the cladding failure temperature [9]. In this analysis, it was assumed that the cladding ruptures at a surface temperature of $1173 \mathrm{~K}$. When the cladding fails, gap release of fission products to the channel starts. CORSOR-M with the surface to volume ratio option was selected to simulate the amount of fission product release from the damaged core.

The pool scrubbing models, adapted from SPARC90 (Suppression Pool Aerosol Removal Code), include the effects of steam condensation at the pool entrance and aerosol deposition by Brownian diffusion, gravitational settling, and inertial impaction, also subjected to evaporative forces, for the rising bubbles [10]. To simulate the pool scrubbing phenomena in spargers, which are located in the incontainment refueling water storage tanks (IRWSTs) and RRTs, the pool scrubbing model in MELCOR was applied following design data.

The calculation of aerosol agglomeration and deposition processes is based on MAEROS (Multicomponent AEROSol), a multisectional and multicomponent aerosol dynamics code that evaluates the size distribution of each type of aerosol mass, or component, as a function of time [11]. To calculate aerosol transport, removal, and release, all of the fission product classes were classified into three components: water, water-soluble particles such as cesium hydroxide $(\mathrm{CsOH})$ and cesium iodide (CsI), and water-insoluble particles. The hygroscopic effect was considered to account for particle growth by water vapor absorption for water-soluble aerosols.

Thermohydraulic and corium conditions of the containment were calculated to determine the break area based on the pressure, hydrogen mole fraction, and ablation depth by molten core-concrete interaction (MCCI) under various containment conditions from the MELCOR analysis results. The rupture area to estimate the amount of released radionuclides to environment was determined for cases in which the containment can be damaged by overpressure or hydrogen burn. The possibility of containment failure was 

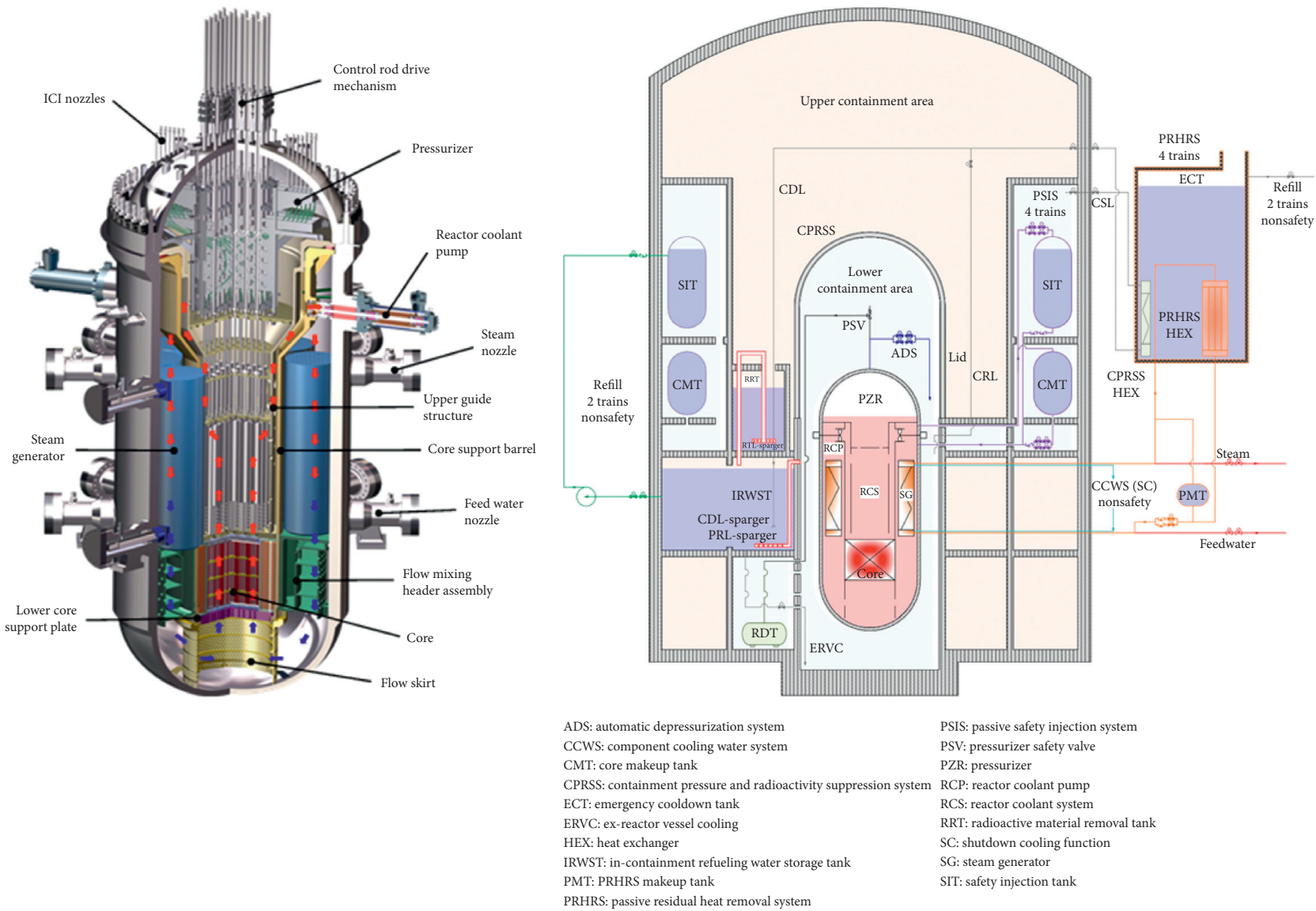

(a)

(b)

Figure 1: Schematics of the SMART: (a) reactor vessel and (b) containment.

assumed when the containment pressure exceeded the design pressure or the hydrogen mole fraction reached $10 \%$. For a potential hydrogen burn, it was also checked whether the steam and oxygen mole fractions were sufficient to generate a burn when the hydrogen mole fraction exceeded the critical value. If the RV fails, MCCI was assumed to occur after the molten corium releases into the cavity. In this analysis, the possibility for containment failure was considered via basemat failure when the axial ablation depth exceeds $3 \mathrm{ft}$.

In cases with no possibility for containment failure, the source term was estimated from the containment natural leak considering design data. The design leak rate from the containment was modeled based on a leak rate of 0.1 volume $\%$ per day. This rate corresponds to a break area of about $1.0 E-6 \mathrm{~m}^{2}$ from the containment to the environment. The source term is indicated as the release fraction of the 12 fission product classes based on their initial inventories in the SMART. It is assumed that all released iodine (I) gases from the fuel combined to form CsI aerosol following previous studies $[12,13]$. The Cs release fraction was highlighted among all fission products to confirm whether the radioactivity of Cs-137 exceeds $100 \mathrm{TBq}$ or not. Source term estimation was performed for $72 \mathrm{~h}$ following the occurrence of the initiating event.
2.2. SMART Core Model. The SMART was designed as an integral reactor meaning that the steam generators, reactor coolant pumps, and pressurizer are installed in the RV. For MELCOR analysis, control volumes for the RV were constructed as shown in Figure 2(a). The coolant heated in the core region (CV170) flows to the steam generator (CV330-CV339) through the reactor coolant pump (CV211-CV212). After cooling in the steam generator, the coolant goes back to the core region through the lower plenum (CV150). In the RV, the pressurizer (CV500) and the core bypass region (CV180) are located at the top and near the core region, respectively. In the MELCOR analysis, the core model was composed of a total of 16 axial levels and 5 rings, as shown in Figure 2(b). The model was arranged to the core region (CV170) and the lower plenum (CV150) of the RV control volumes. Among the 16 axial levels, a total of 10 axial levels (\#6 to \#15) contain active fuel with 5 rings. Axial level \#5 simulates the core support plate, and axial level \#16 is the upper plenum region. Each axial level of the active fuel contains about 1.6 tons of uranium dioxide, about 0.3 tons of zircaloy, about 0.03 tons of steel, and about 0.07 tons of control poison. More than about 14 tons of steel is contained in the lower plenum including the core support plate. In summary, about 16 tons of uranium dioxide, about 4 tons of zircaloy, about 15 tons of steel, and 0.7 tons of 


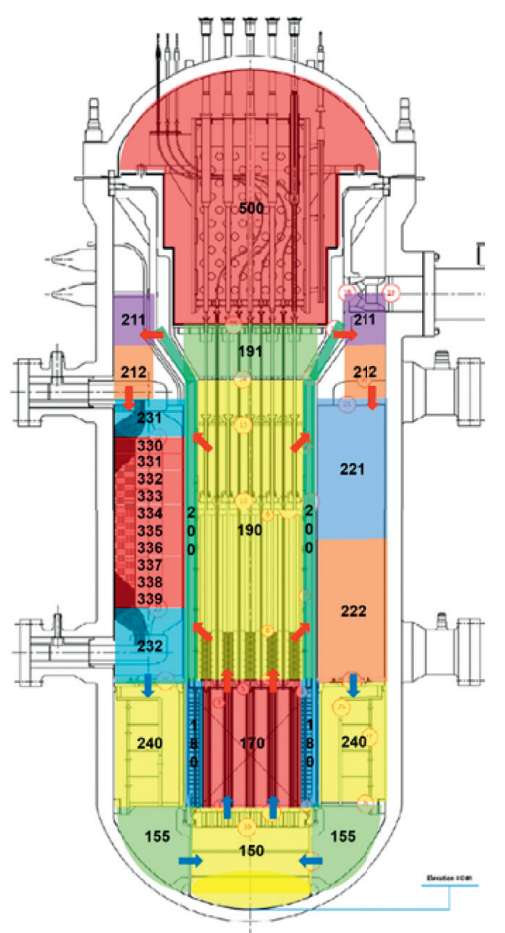

(a)

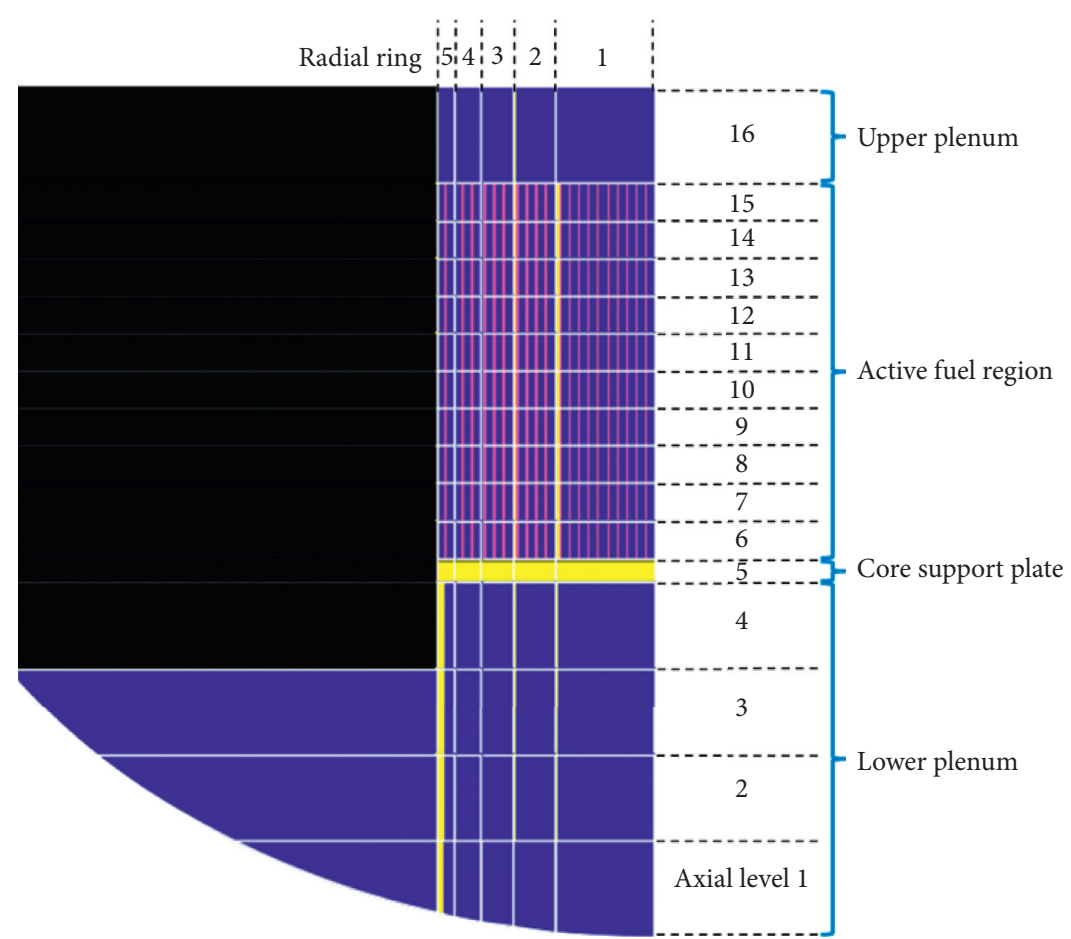

(b)

FIGURE 2: MELCOR nodalization for SMART: (a) reactor vessel and (b) core.

control poison, in total about 36 tons, are contained in the core model for MELCOR analysis. In order to accurately calculate lower head failure, the lower head was divided into 10 segments considering radial and axial nodalization of the fuel. The lower head wall consists of five nodes, with the temperature of the structures and the pressures determining vessel failure.

\subsection{SMART Containment Model. The containment of the} SMART consists of two sections: a lower containment area (LCA) and an upper containment area (UCA). For MELCOR analysis, the LCA was classified into several control volumes such as upper and lower annulus, cavity, core make-up tank room, and safety injection tank (SIT) room, as shown in Figure 3(a). The UCA is divided into three bulk volumes and a refueling pool. The total volumes of the LCA and the UCA are about $10,000 \mathrm{~m}^{3}$ and $50,000 \mathrm{~m}^{3}$, respectively. In the MELCOR analysis, the initial pressure and temperature of the containment control volumes were assumed as atmospheric pressure and $312 \mathrm{~K}$, respectively.

The LCA is connected to the UCA through the containment pressure and radioactivity suppression system (CPRSS) that envelops the RV. This system consists of (i) four water tanks, namely, two IRWSTs and two RRTs, each of which has a different volume, and (ii) flow paths for water and gas. The water volumes of IRWST1 and IRWST2 are, respectively, about $1,200 \mathrm{~m}^{3}$ and $2,500 \mathrm{~m}^{3}$, and these two tanks are connected via pipelines at the bottom, whereas the two RRTs are not connected. RRT1 and RRT2, respectively, contain water volumes of about $160 \mathrm{~m}^{3}$ and $330 \mathrm{~m}^{3}$. Half of the RRT pool surface is open to the UCA. The tanks (IRWST1-RRT1 and IRWST2-RRT2) are connected by reversed U-shaped pipelines without valves. In the MELCOR analysis, the initial water temperature of the IRWST and the RRT was conservatively assumed as $322 \mathrm{~K}$.

Likewise, the flow paths connecting the LCA and the IRWSTs are always open; these flow paths are indicated as green lines in Figure 3(a). The CPRSS can maintain UCA pressure below LCA pressure because steam condenses during transportation. As stated in the previous section, aerosol and fission product vapor can be removed by scrubbing within the IRWST and the RRT.

If the pressure in the SIT room located at the top of the LCA exceeds $1.6 \mathrm{bar}$, operators open the flow paths to transport excessive steam to the IRWSTs through a heat exchanger in an emergency cool-down tank until the core exit temperature meets the entry condition of severe accident management guidance (SAMG); these flow paths are indicated as purple lines in Figure 3(a). Safety relief valves and an automatic depressurization system (ADS) are installed on the upper head of the pressurizer. The safety relief valve is a passive safety valve that prevents the RV from high pressure failure by releasing steam to the cavity when the pressure in the pressurizer exceeds 170 bar.

After SAMG entry, it was assumed that operators open the flow paths connecting the SIT room and the RRT and initiate the ADS, which is an active system to depressurize the RV by releasing gas to the RRT; these flow paths are indicated as red lines in Figure 3(a). The SAMG entry condition was assumed to be satisfied when the core exit gas temperature exceeds $923 \mathrm{~K}$. The operator action time was 


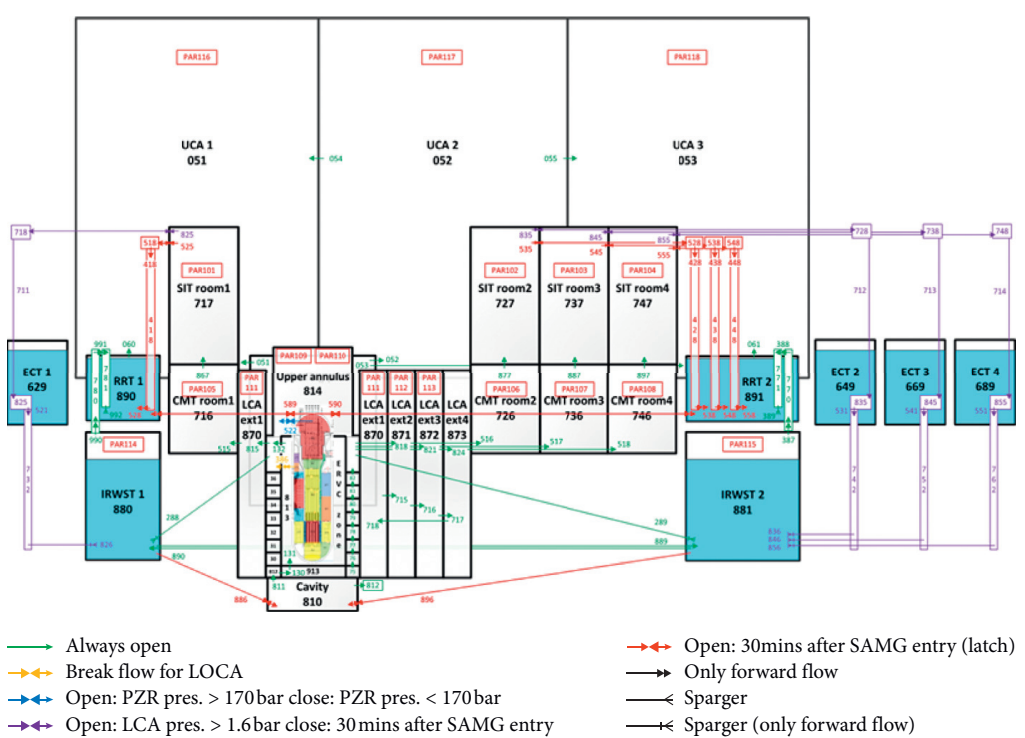

(a)

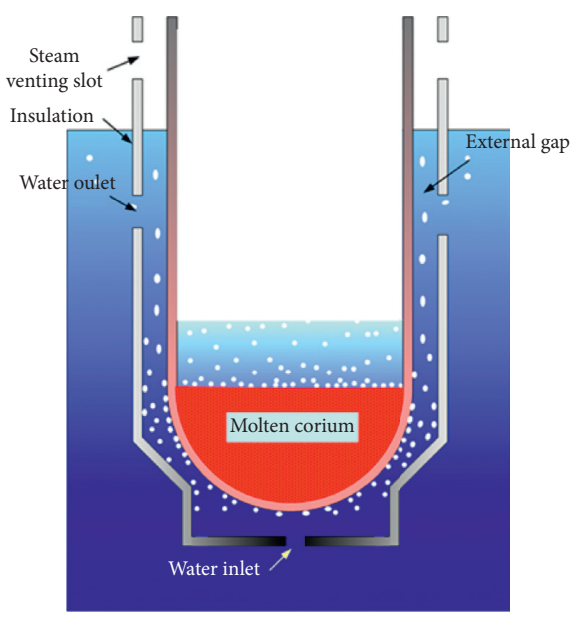

(b)

Figure 3: (a) MELCOR nodalization for SMART containment and (b) conceptual view of ex-reactor vessel cooling.

assumed as $30 \mathrm{~min}$ for initiating the ADS and opening the flow path connecting the SIT room and the RRT. Passive autocatalytic recombiners (PARs) are installed to prevent hydrogen burn in the LCA, the UCA, and the IRWST, as shown in Figure 3(a). In the MELCOR analysis, an NIS-type PAR was modeled to operate when the hydrogen and oxygen mole fractions reach $2 \mathrm{vol} \%$ and $3 \mathrm{vol} \%$, respectively. After both mole fractions fall below $0.5 \mathrm{vol} \%$, the PAR was assumed to stop. Also, operators can initiate the ACSS when available. Located at the top of the UCA, the ACSS uses a water source outside of the containment. Sprayed water accumulates in the refueling pool located at the bottom of the UCA.

In the SMART, ex-reactor vessel cooling (ERVC) is available to prevent RV failure when in-vessel core degradation occurs; Figure 3(b) shows a conceptual view of ERVC. Operators initiate the cavity flooding system (CFS) after SAMG entry to inject coolant into the cavity from the IRWST by gravitational force. The coolant fills up to almost half the height of the LCA annulus, so that boiling occurs in the ERVC zone by the residual heat from the lower head vessel. There is no direct heat transfer from the ERVC zone to the lower annulus, which is located outside the ERVC zone by an insulator. To avoid excessive steam condensation in the MELCOR analysis, the lower annulus was divided into several control volumes to decrease the temperature difference between the steam and water surface by simulating a thermal stratification of the water [14].

2.4. Accident Condition. In this research, a 2-in diameter guillotine break SBLOCA in the PSIS was considered as the initiating event; the flow path for the break is indicated as the yellow line in Figure 3(a), representing the coolant inside of the RV discharging to the upper annulus through the break area. It was assumed that the PRHRS and the PSIS are unavailable but the CFS is available during the accident. If safety systems are available, potential severe accidents can be delayed or even arrested. Although the probability is very low, this severe accident scenario was considered to analyze the containment integrity under the most conservatively defined pressurization condition.

The RV condition and the availability of the RRT and the ACSS were considered as containment condition variables. The source term as well as containment safety can be affected by the condition of the RV because fission products are released into the LCA in a SBLOCA. The status of the RV depends on the success of on-time CFS operation when the PSIS and the PRHRS are unavailable. Two different CFS initiation times after SAMG entry were considered for early and late operation: $30 \mathrm{~min}$ (case 0 , the base case) and $72 \mathrm{~h}$ (case 1).

Before environmental release, fission products pass the RRT and the UCA, and thus source terms can be affected by the availability of the RRT and the ACSS. In the two above cases, the RRTs were assumed to be in a normal state with $100 \%$ water capacity, while the ACSS was unavailable. On the other hand, two other cases assumed that there is no water in the RRTs following SBLOCA occurrence (cases 3 and 4). To analyze the effect of the containment spray on the UCA condition and the source term, the ACSS was assumed to be available in two cases (cases 2 and 4). Table 1 shows the characteristics of the analysis cases.

\section{Results and Discussion}

3.1. Source Term Estimation according to $R V$ Condition. Prior to the accident analysis, the steady state was simulated to validate the MELCOR input model. As shown in Table 2, the result fit well to the SMART design operating conditions. This section covers cases 0 and 1 according to the RV condition; as previously mentioned, cases 0 and 1 represent 
TABLE 1: Characteristics of the analysis cases.

\begin{tabular}{lccc}
\hline Case & $\begin{array}{c}\text { Initiation time of the cavity flooding } \\
\text { system }\end{array}$ & $\begin{array}{c}\text { Water capacity of the radioactive removal } \\
\text { tank (\%) }\end{array}$ & $\begin{array}{c}\text { Availability of the ancillary containment spray } \\
\text { system }\end{array}$ \\
\hline 0 & Early & 100 & Unavailable \\
1 & Late & 100 & Unavailable \\
2 & Early & 100 & Available \\
3 & Early & 0 & Unavailable \\
4 & Early & 0 & Available \\
\hline
\end{tabular}

Early: $30 \mathrm{~min}$ after SAMG entry; late: $72 \mathrm{~h}$ after SAMG entry.

TABLE 2: Comparison of the SMART operating conditions and MELCOR results.

\begin{tabular}{lccc}
\hline Parameter & Unit & SMART design value & MELCOR result \\
\hline Core heat output & $\mathrm{MW}$ & 365 & 365.7 \\
Core inlet coolant flow rate & $\mathrm{kg} / \mathrm{s}$ & 2507 & 2449 \\
Core inlet temperature & $\mathrm{K}$ & 568.7 & 585.4 \\
Core outlet temperature & $\mathrm{K}$ & 594.1 & 608.3 \\
Pressurizer pressure & $\mathrm{MPa}$ & 1.50 & 1.49 \\
Steam flow rate (per SG) & $\mathrm{kg} / \mathrm{s}$ & 47.7 & 47.6 \\
Feed water flow rate (per SG) & $\mathrm{kg} / \mathrm{s}$ & 47.7 & 47.7 \\
SG inlet feed water temperature & $\mathrm{K}$ & 503.2 & 503.0 \\
SG outlet steam pressure & $\mathrm{MPa}$ & 5.62 & 5.77 \\
\hline
\end{tabular}

SG: steam generator.

early and late CFS initiation (30 min and $72 \mathrm{~h}$ after SAMG entry), respectively.

Table 3 shows the main event times in the analysis of the SBLOCA-induced severe accident. The reactor tripped by the pressurizer low-level signal following SBLOCA occurrence at $0 \mathrm{~h}$; it was assumed that the reactor coolant pumps and the main feedwater pumps were halted at the same time. The collapsed liquid level in the RV decreased, as shown in Figure 4(a), so that the fuel top was exposed at $0.24 \mathrm{~h}$. The core exit temperature met the SAMG entry condition of $923 \mathrm{~K}$ at $2.09 \mathrm{~h}$. Hydrogen and fission products started to release into the containment at $2.2 \mathrm{~h}$ and $2.25 \mathrm{~h}$, respectively. The operators initiated the ADS 30 min after SAMG entry to transport the gas inside of the RV to the UCA through the RRTs; early CFS initiation was performed at the same time in case 0 . Because of the ERVC, the core support plate failure was delayed about $1 \mathrm{~h}$ in case 0 , after which the total mass in the RV lower head rapidly increased, as shown in Figure 4(b). But, in case 1, the mass drastically decreased at 19.09 h due to RV failure. At the same time, MCCI started and the late CFS initiation was performed at $74.09 \mathrm{~h}$, which is $72 \mathrm{~h}$ after SAMG entry.

Figure 5(a) shows the collapsed liquid level in the LCA annulus and ERVC system. In the figure, the reference level $(0 \mathrm{~m})$ corresponds to the bottom of the cavity (CV810 in Figure 3(a)). When operators initiate the CFS, the liquid levels in the LCA annulus and the ERVC system increase to the same level in both cases 0 and 1 . The liquid level in the LCA annulus prior to CFS initiation was caused by leakage through the break. In case 1 , the liquid level started to decrease due to MCCI after about $19 \mathrm{~h}$. Because of the temperature stratification in the water of the LCA annulus, excessive steam condensation can be prevented in MELCOR, so that the containment pressure can be realistically estimated. The axial and radial ablation depth of the cavity started to increase at about $36 \mathrm{~h}$ after the water in the cavity was depleted in case 1, as shown in Figure 5(b). The ablation stopped after late CFS initiation. As the basemat is located $3 \mathrm{ft}$ below the cavity concrete, it was estimated that damage to the basemat can be prevented even with late CFS initiation.

The UCA pressure remained below the LCA pressure during the accident by the CPRSS, as shown in Figure 6(a). The containment pressure increases right after the SBLOCA occurs. But the LCA pressure decreased drastically at $2.59 \mathrm{~h}$ following the transport of massive steam to the UCA through the flow path connecting the SIT room and the RRT 30 min after the SAMG entry. During the transportation, most of the steam condensed in the RRT such that the UCA pressure was barely changed. In case 1, the LCA pressure started to decrease because there was no additional steam supply to the LCA after the lower plenum dry-out at $13.71 \mathrm{~h}$, while the steam condensed to the heat structures and cavity water surface. However, the LCA pressure rapidly increased when the RV failed because of instantaneous water evaporation in the cavity. The final pressures of the LCA and UCA were similar in both cases. As the design pressures of the LCA and UCA are $350 \mathrm{kPa}$ and $190 \mathrm{kPa}$, respectively, sufficient safety margin exists for containment failure by overpressurization.

As shown in Figure 6(b), the maximum hydrogen mole fraction in case 0 was analyzed to be about $3 \%$ in the LCA. Over time, the mole fraction decreased as the hydrogen transported to the UCA. In case 0 , because the molten corium was successfully retained in vessel by the ERVC, the mole fraction was maintained in the containment until $72 \mathrm{~h}$. But, in case 1, the maximum hydrogen mole fraction exceeded the critical value, $10 \%$, in the LCA. After the water 
TABLE 3: Main event times from MELCOR analysis for the small break loss-of-coolant accident in the SMART.

\begin{tabular}{|c|c|c|c|c|c|}
\hline Main event & Case 0 (hours) & Case 1 (hours) & Case 2 (hours) & Case 3 (hours) & $\begin{array}{c}\text { Case } 4 \\
\text { (hours) }\end{array}$ \\
\hline SBLOCA occurrence & 0.00 & 0.00 & 0.00 & 0.00 & 0.00 \\
\hline Reactor, reactor coolant pump, and main feedwater pump trip & 0.04 & 0.04 & 0.04 & 0.04 & 0.04 \\
\hline Fuel top exposure & 0.24 & 0.24 & 0.24 & 0.23 & 0.23 \\
\hline Fuel bottom exposure & 2.00 & 2.00 & 2.00 & 2.04 & 2.04 \\
\hline SAMG entry & 2.09 & 2.09 & 2.09 & 2.24 & 2.24 \\
\hline Oxidation start & 2.20 & 2.20 & 2.20 & 2.28 & 2.28 \\
\hline Gap release start & 2.25 & 2.25 & 2.25 & 2.32 & 2.32 \\
\hline Candling start & 2.47 & 2.47 & 2.47 & 2.62 & 2.62 \\
\hline ADS initiation & 2.59 & 2.59 & 2.59 & 2.74 & 2.74 \\
\hline CFS initiation (early) & 2.59 & N/A & 2.59 & 2.74 & 2.74 \\
\hline ACSS initiation & $\mathrm{N} / \mathrm{A}$ & $\mathrm{N} / \mathrm{A}$ & 4.09 & $\mathrm{~N} / \mathrm{A}$ & 4.24 \\
\hline Core support plate failure & 9.19 & 8.02 & 9.69 & 8.01 & 9.57 \\
\hline Lower plenum dry-out & 16.88 & 13.71 & 18.95 & 16.64 & 16.40 \\
\hline RV failure & N/A & 19.09 & $\mathrm{~N} / \mathrm{A}$ & $\mathrm{N} / \mathrm{A}$ & $\mathrm{N} / \mathrm{A}$ \\
\hline MCCI start & $\mathrm{N} / \mathrm{A}$ & 19.09 & N/A & $\mathrm{N} / \mathrm{A}$ & $\mathrm{N} / \mathrm{A}$ \\
\hline CFS initiation (late) & N/A & 74.09 & N/A & N/A & $\mathrm{N} / \mathrm{A}$ \\
\hline
\end{tabular}

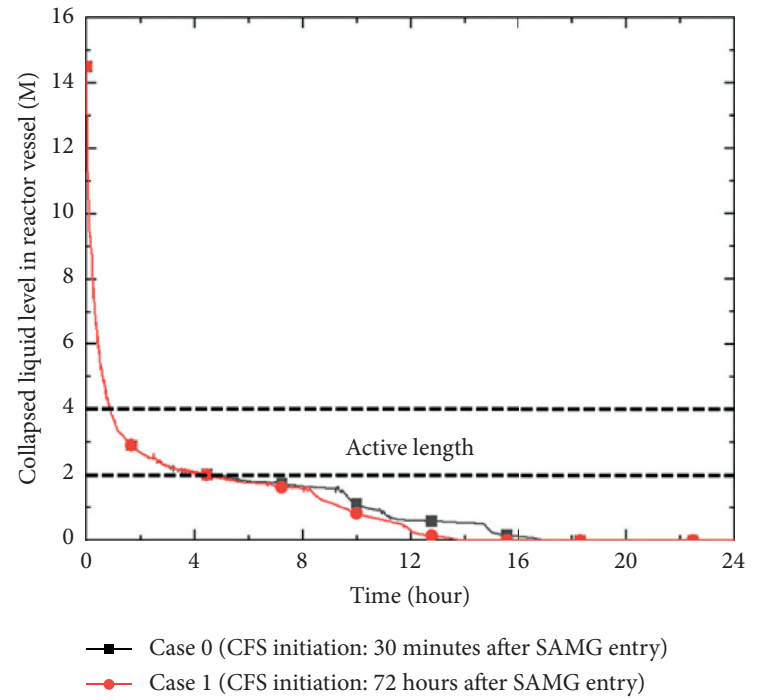

(a)

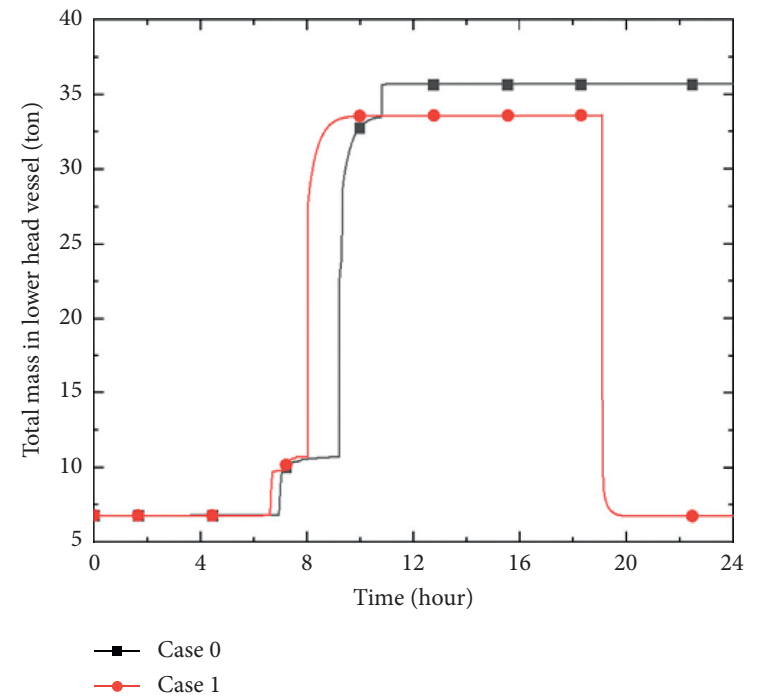

(b)

Figure 4: (a) Collapsed liquid level in the reactor vessel and (b) total mass in the lower head vessel.

in the cavity depleted, metals such as zirconium and steel started to oxidize, which in turn started to increase the mole fractions of hydrogen and carbon monoxide at about $36 \mathrm{~h}$, as shown in Figure 6(c). Although the peak hydrogen mole fraction was about $11 \%$, it is estimated that a hydrogen burn is very unlikely to occur because the oxygen mole fraction is too low and the steam mole fraction is too high in the LCA. The operational condition for the PARs was satisfied only in the UCA of case 1, as shown in Figure $6(\mathrm{~d})$. Because the oxygen mole fraction is too low, the PAR did not operate in the LCA. Following reaction with the metals, carbon dioxide also started to increase at about $48 \mathrm{~h}$ when the molten corium converted from the heavy mixture (with a higher density than the metallic phase) into the light oxide (with a lower density than the metallic phase).
The results demonstrate that containment failure can be prevented considering the pressure, hydrogen mole fraction, and ablation depth. Therefore, only the design leak was considered to estimate the source term. Figure 7 shows the release fractions of the 12 classes to the environment in cases 0 and 1 . The noble gases were continuously released such that their release fractions were the largest among all fission products. For all other fission products (except the noble gases), the release fractions to the environment increased until $12 \mathrm{~h}$ and then were maintained. The release fractions of Cs, tellurium, and CsI showed the highest values excluding the noble gases, and the values were similar in both cases. The metallic fission products that are low volatile radionuclides, such as cerium and ruthenium, were released when the gas in the RV transported to the cavity by the RV failure in case 1. Additional release of metallic fission products 


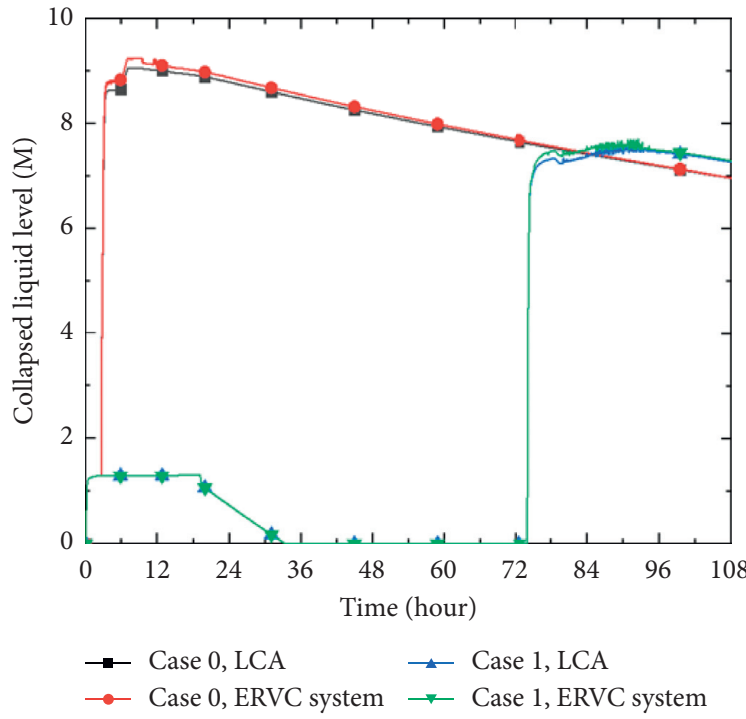

(a)

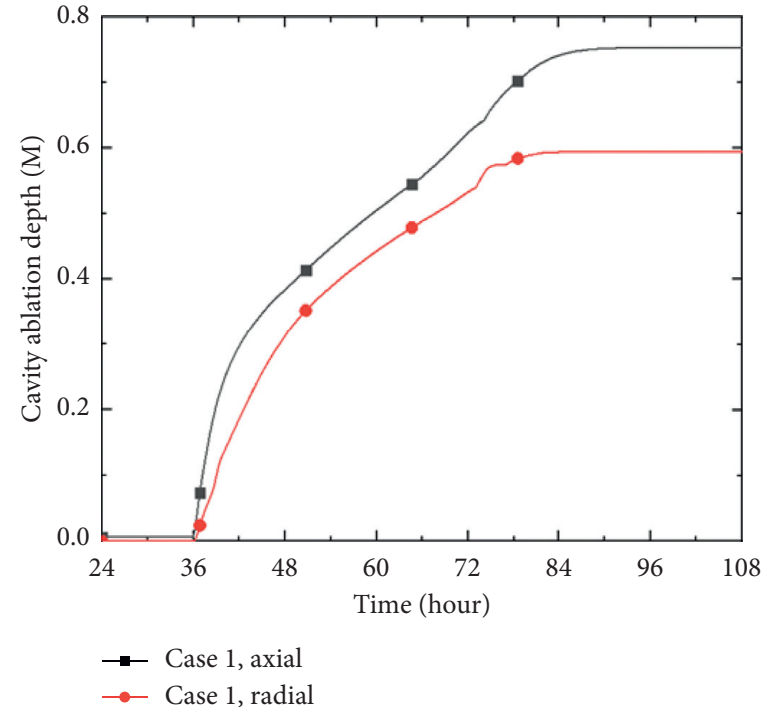

(b)

Figure 5: (a) Collapsed liquid level $(0 \mathrm{~m}=$ bottom of the cavity) in the lower containment area and ex-reactor vessel cooling system; (b) ablation depths of the cavity.

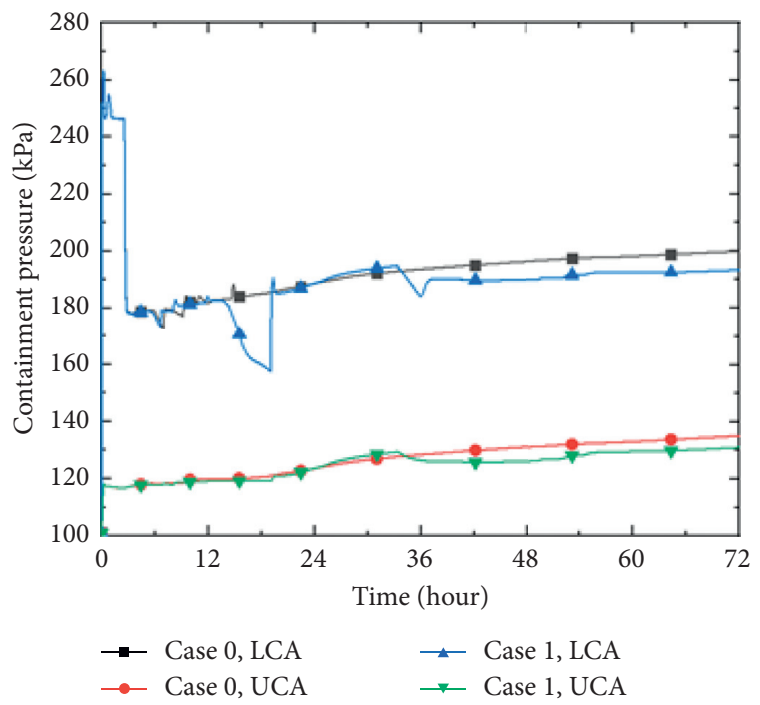

(a)

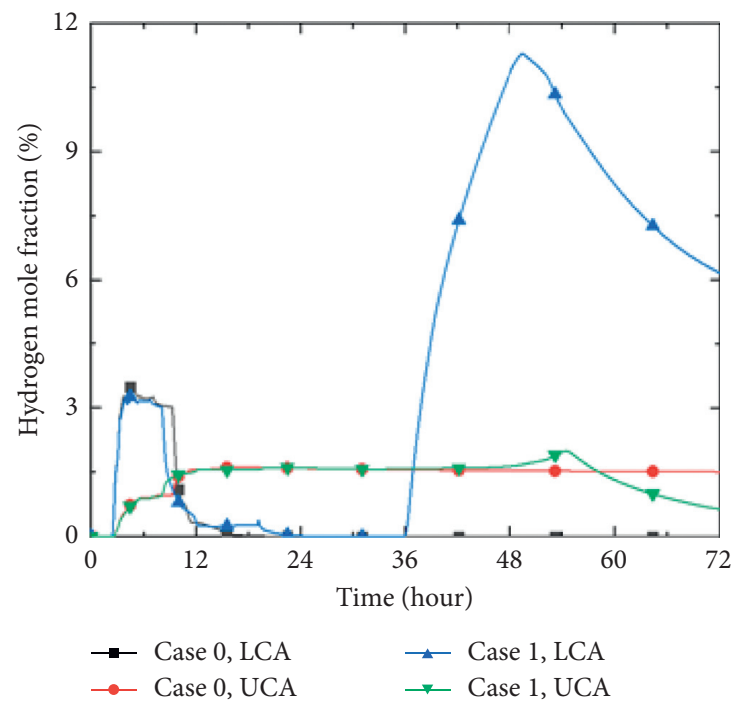

(b)

FIgUre 6: Continued. 


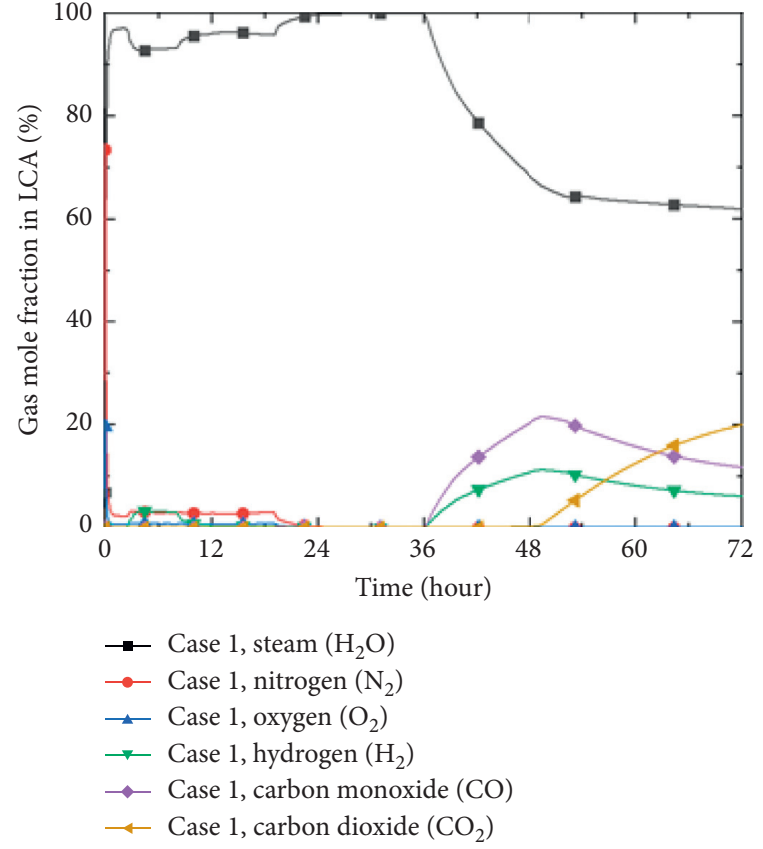

(c)

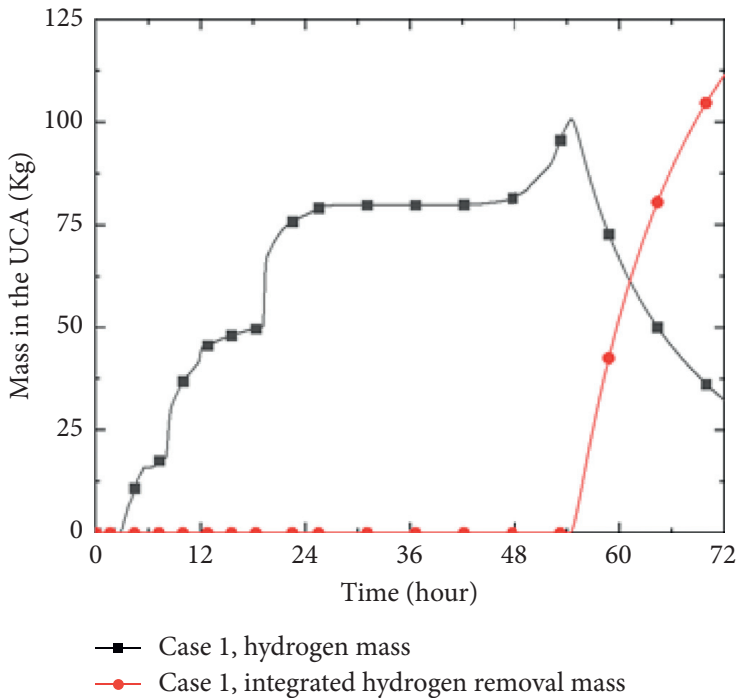

(d)

FIgURE 6: Containment properties from the MELCOR analysis: (a) pressure, (b) hydrogen mole fraction, (c) gas mole fraction in the lower containment area, and (d) hydrogen mass and integrated hydrogen removal mass in the upper containment area.

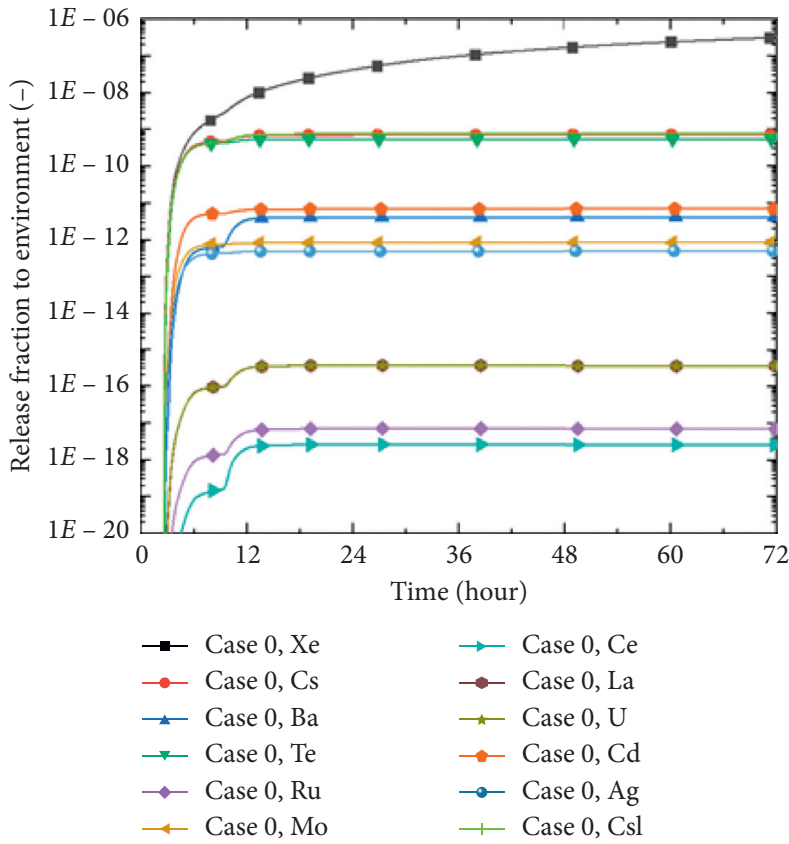

(a)

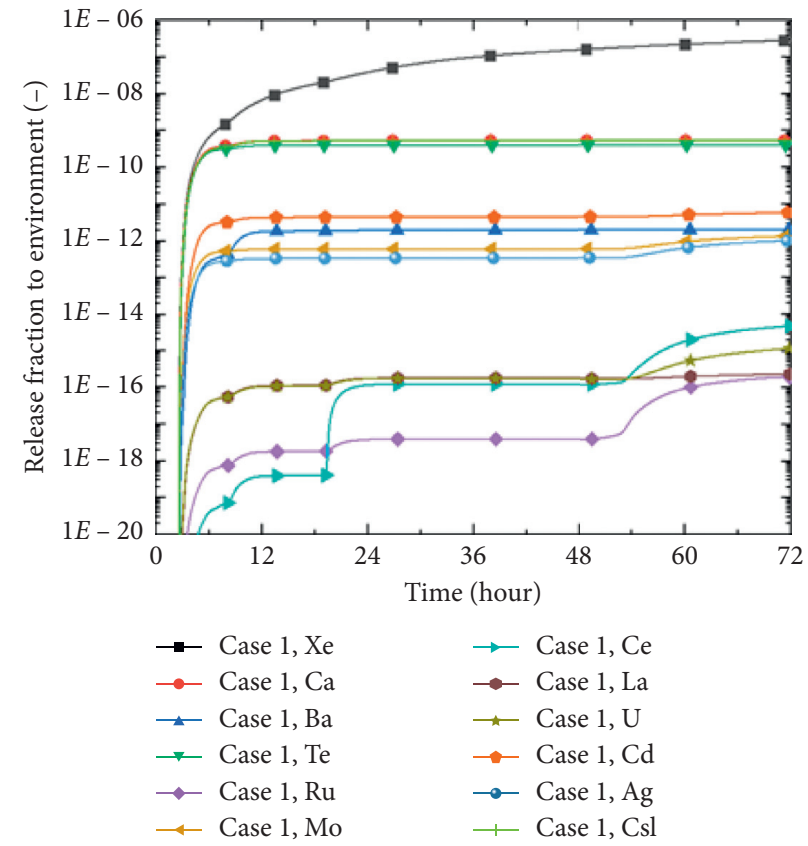

(b)

Figure 7: Release fraction to the environment: (a) case 0 and (b) case 1.

started after the molten corium changed to light oxide at about $48 \mathrm{~h}$.

Figure 8 shows the in-containment Cs release fractions. In both cases, the release fraction to the UCA could be maintained below that to the LCA because of the RRTs. The release fraction to the LCA was higher than the release fraction to the RRTs because the accumulated total flow through the break area was larger, since the gap release started at about $2 \mathrm{~h}$, as shown in Figure 9(a). The flow rate increased when the RV pressure increased in both cases, as shown in Figure 9(b). This 


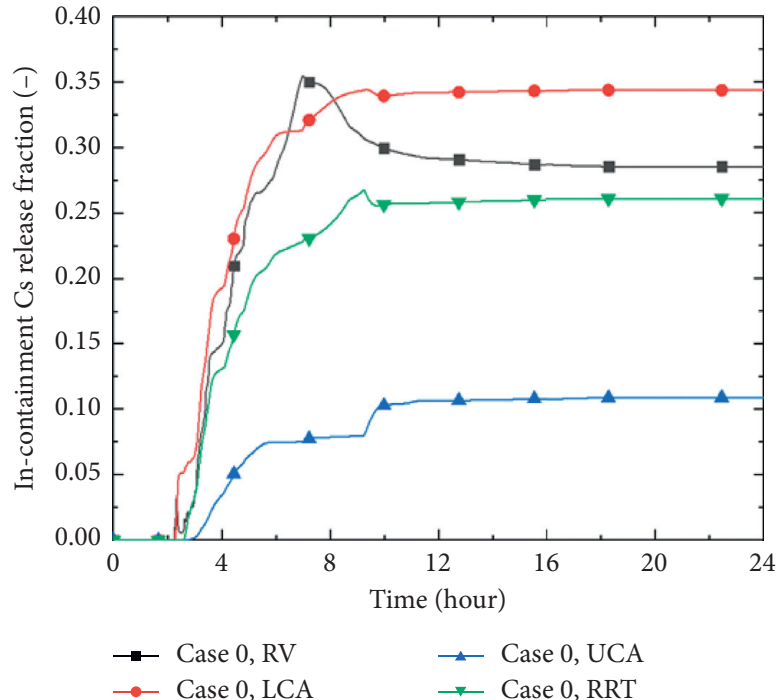

(a)

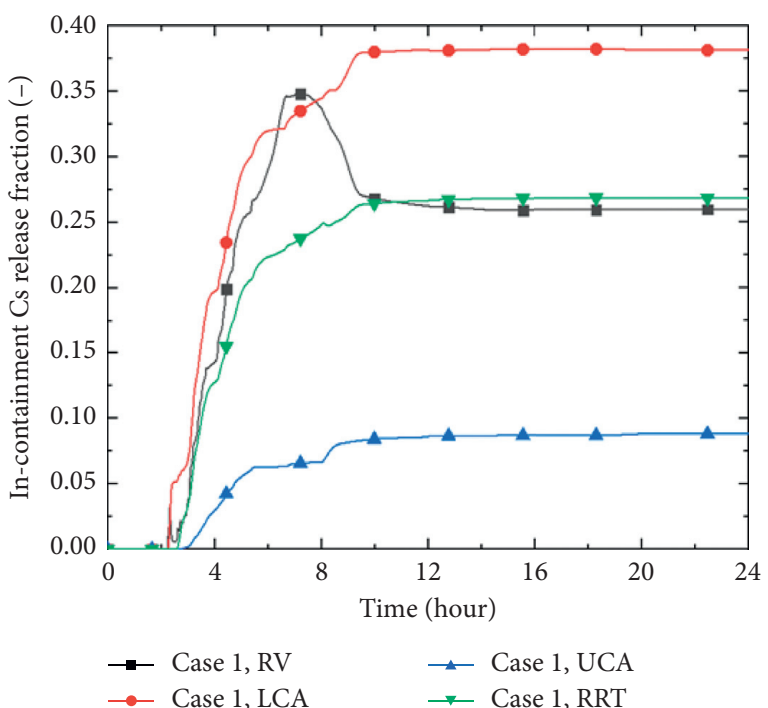

(b)

FIGURE 8: In-containment cesium release fraction: (a) case 0 and (b) case 1.

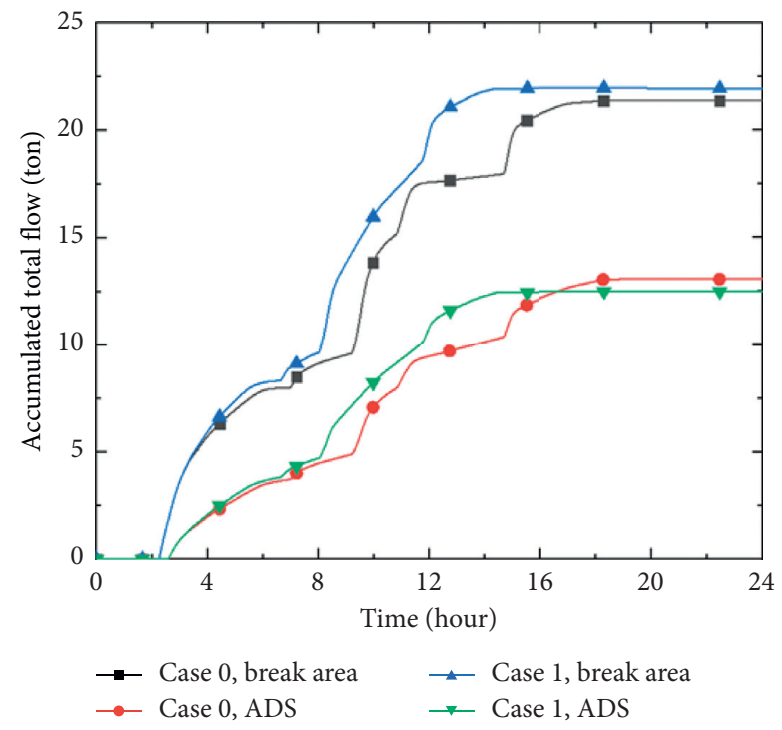

(a)

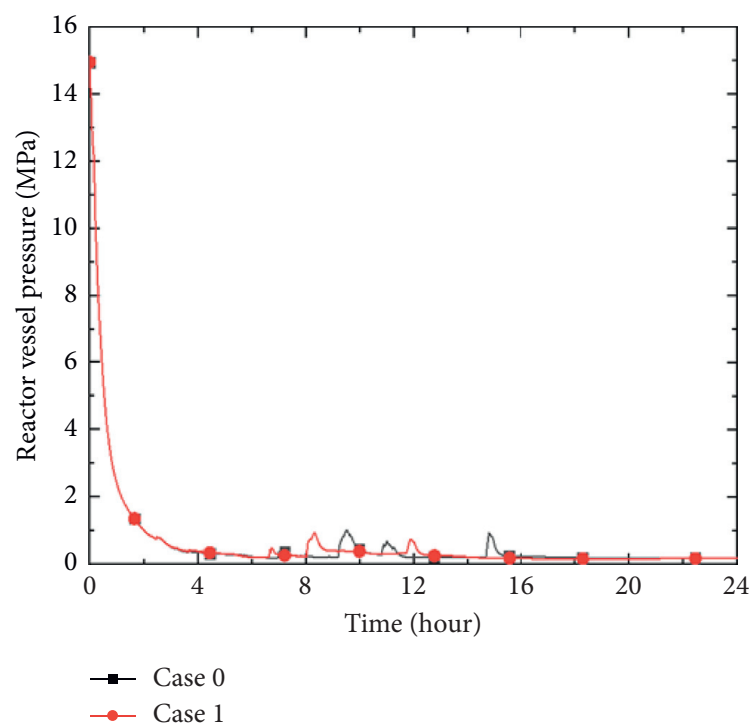

(b)

Figure 9: (a) Total accumulated flow through the break area and the automatic depressurization system from the reactor vessel from the start of gap release; (b) pressure in the reactor vessel.

is because the steam mass in the RV increases when the core support plate fails, and convective heat transfer from the molten pool increases by degradation. About $25 \%$ of the Cs was scrubbed in the RRTs, which verifies its performance in suppressing the release of fission products.

3.2. Source Term Estimation according to RRT and ACSS Availability. In this section, cases $0,2,3$, and 4 are covered according to the availability of the RRT and the ACSS as shown in Table 1. In cases 2 and 4, it was assumed that operators initiate the ACSS $2 \mathrm{~h}$ after SAMG entry, with twohour cyclic operation assumed for the ACSS (in other words, operation cycles of two hours per cycle every two hours). In cases 3 and 4, depletion of the RRT water was assumed following accident occurrence. Due to the absence of the RRT water, the amount of residual heat removal by the IRWST increased, so that the core exit temperature can be delayed in these cases. Early CFS operation was assumed for all four cases in this section. 


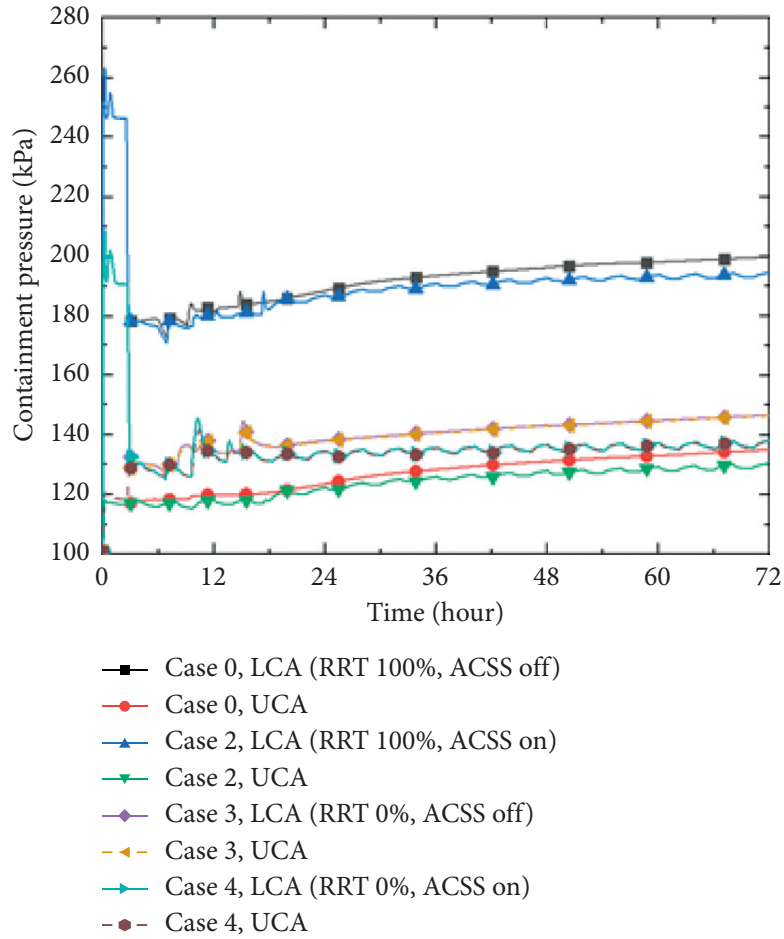

(a)

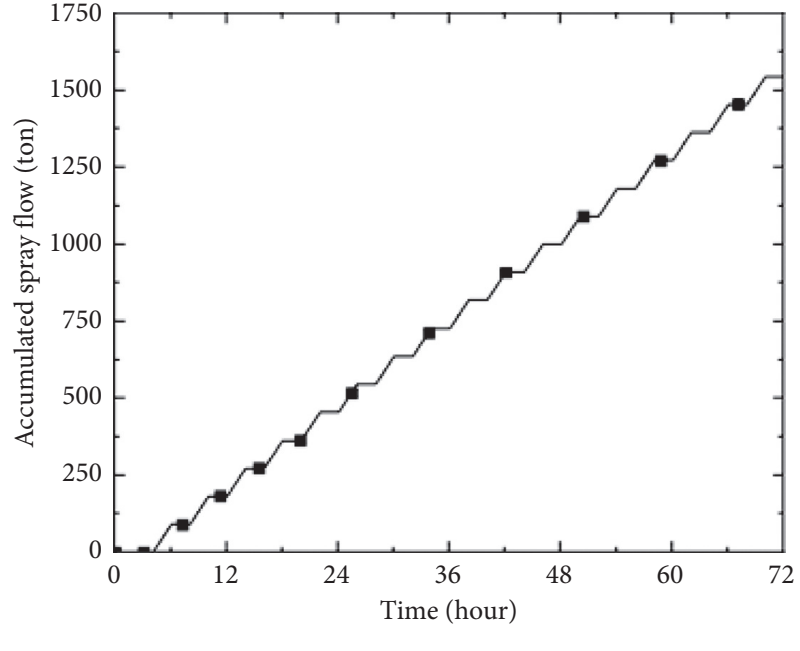

Case 2, 4 (ACSS on)

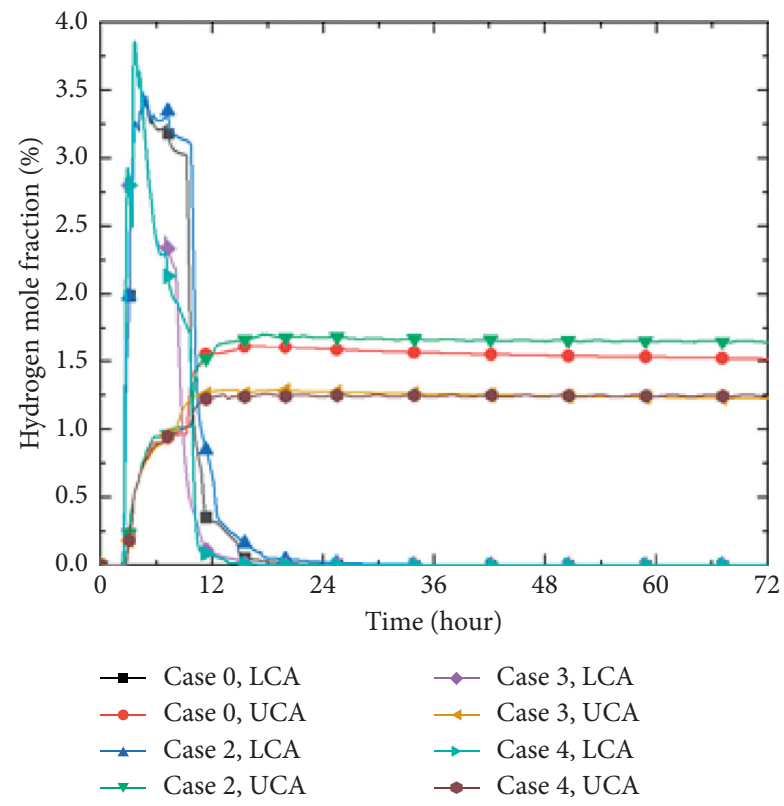

(c)

FIGURE 10: Containment properties from the MELCOR analysis: (a) pressure, (b) accumulated spray flow by the ancillary containment spray system, and (c) hydrogen mole fraction.

As shown in Figure 10(a), the pressures in the LCA and the UCA were the same in cases 3 and 4 because there was no water in the RRTs, which are passages between the two areas. In cases 2 and 4, as shown in Figure 10(b), the final pressure lowered with fluctuation because of ACSS operation, from which about 1,500 tons of spray flow was accumulated. The overall hydrogen mole fractions in the LCA and UCA were similar in all four cases $(0,2,3,4)$, as shown in Figure 10(c). Also, the PARs did not operate in the containment in any of these cases because the operational condition was not satisfied. As sufficient safety margins exist for containment pressure and hydrogen mole 


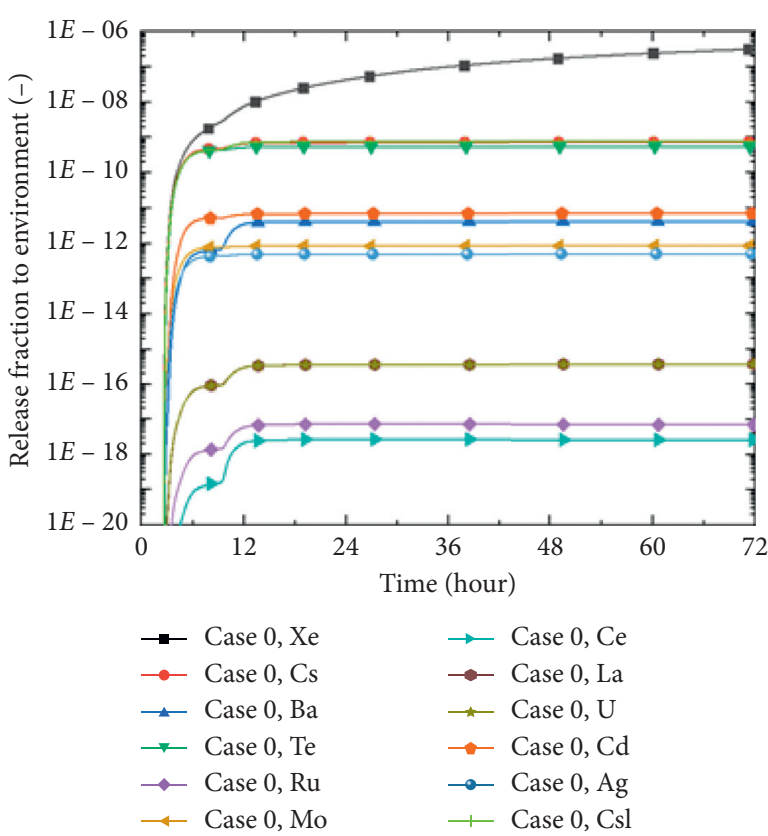

(a)

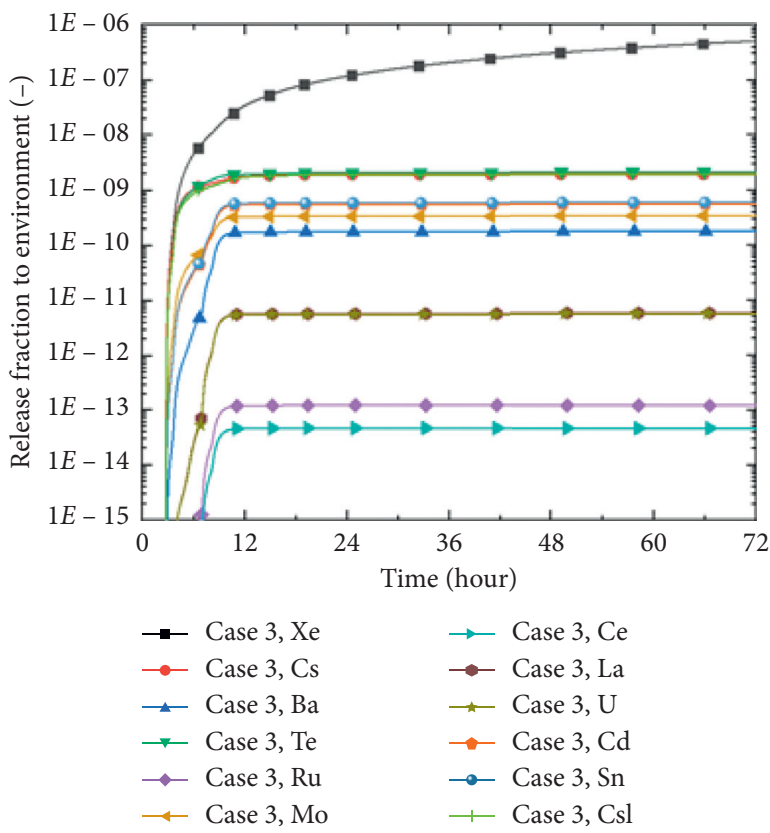

(c)

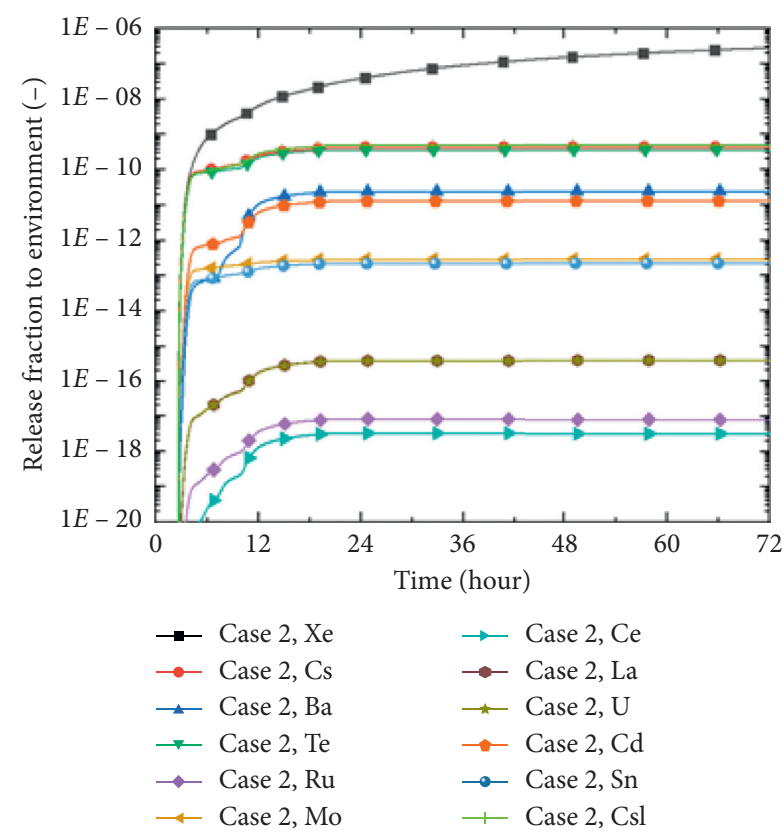

(b)

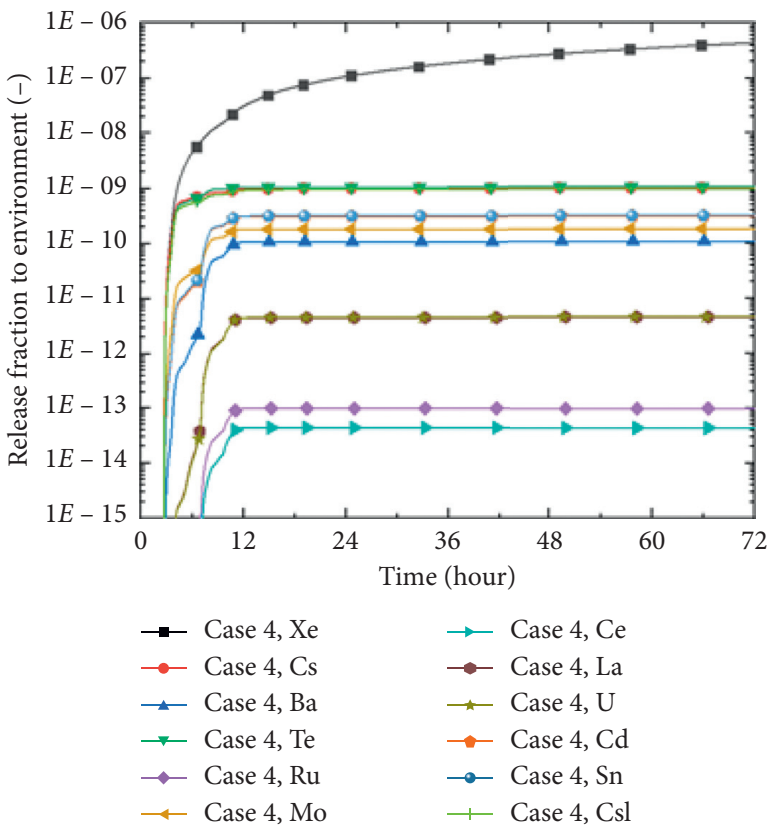

(d)

Figure 11: Release fractions to the environment: (a) case 0, (b) case 2, (c) case 3, and (d) case 4.

fraction without RV failure, containment failure can be prevented in these cases.

Figure 11 shows the release fractions of the 12 classes to the environment in cases $2-4$. The behaviors of the release fractions in cases 2-4 were similar to that in case 0 . The release fractions increased until $12 \mathrm{~h}$ and remained in all cases. The Cs release fraction in case 3 had the largest value compared to case 0 - the release fraction more than doubled in case 3. However, the release fraction can be halved if the ACSS is available. Figure 12 shows the in-containment Cs release fractions for cases $2-4$. In cases 3 and 4 , the release fraction to the UCA includes the release fraction to the RRTs. The in-containment Cs release fractions according to ACSS availability do not significantly differ because the sump of the sprayed water is the refueling pool located at the bottom of the UCA. 


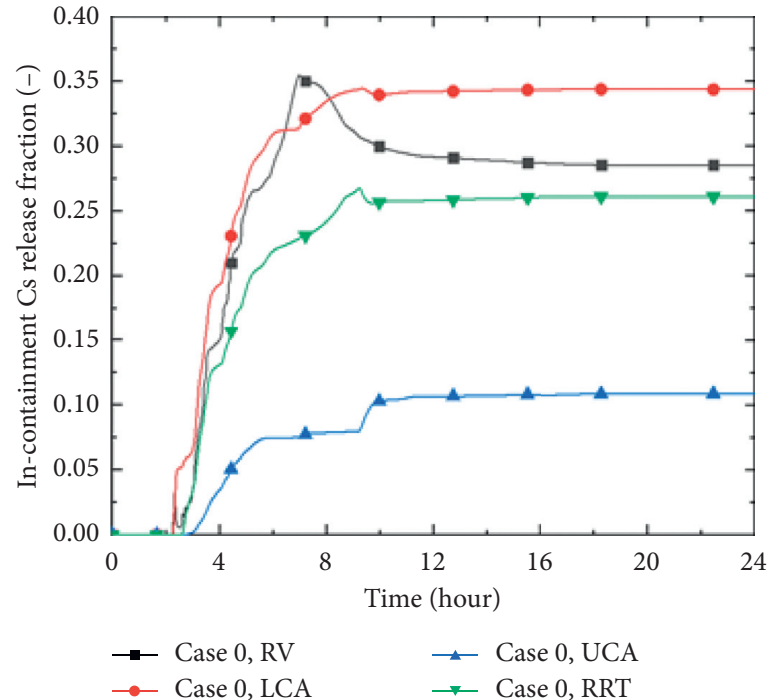

(a)

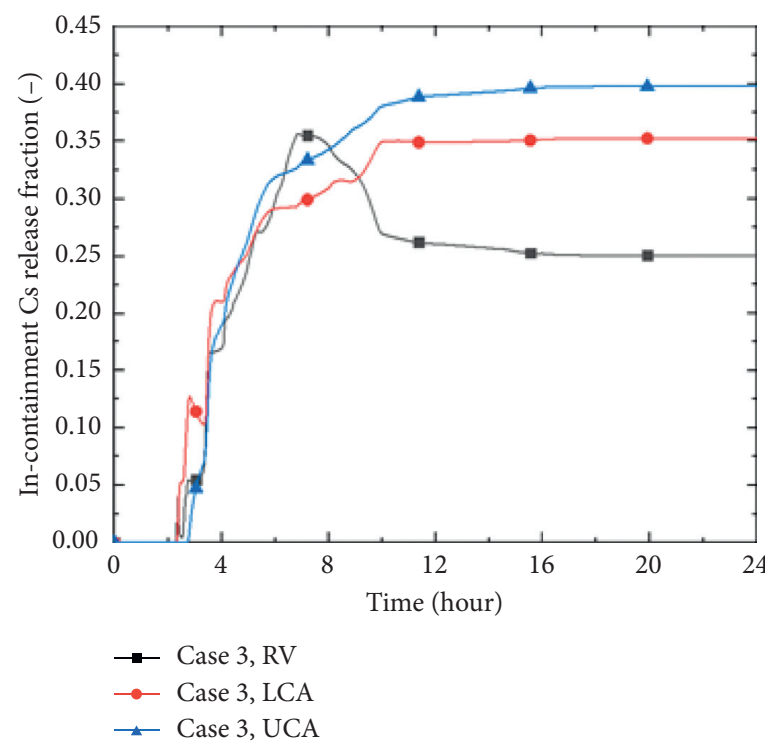

(c)

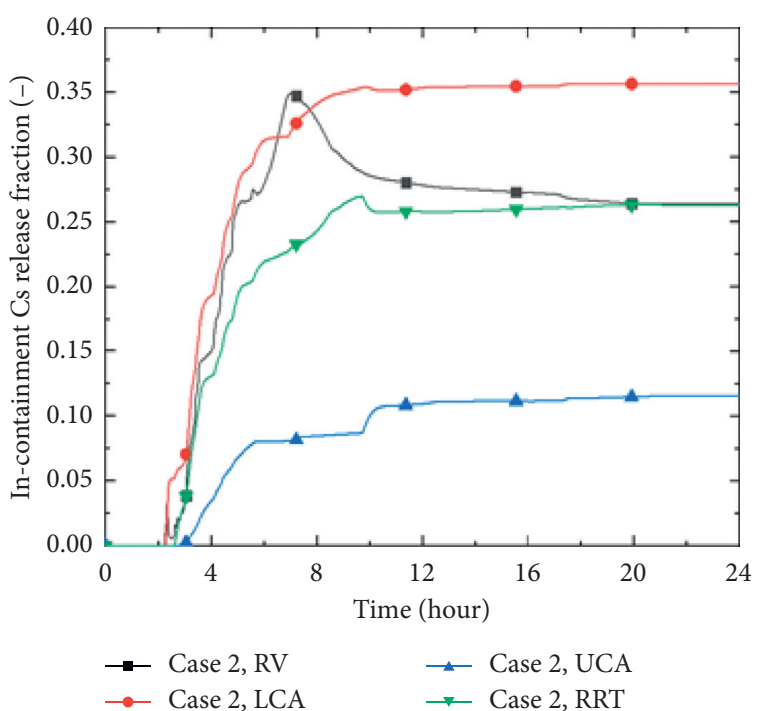

(b)

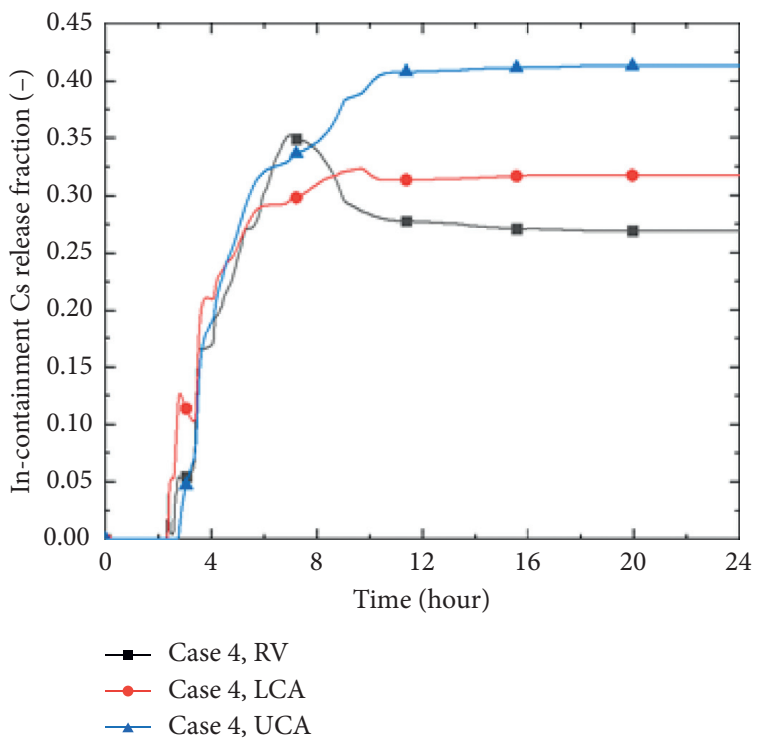

(d)

FIgURE 12: In-containment cesium release fractions: (a) case 0, (b) case 2, (c) case 3, and (d) case 4.

\section{Conclusion}

In this study, source term estimation under the SBLOCAinduced severe accident condition in the SMART was performed using MELCOR. First, the source term according to the RV condition was estimated. When early CFS initiation is possible (case 0 in this work), the integrity of the RV can be maintained by the ERVC for $72 \mathrm{~h}$. If operators initiate the CFS $72 \mathrm{~h}$ after SAMG entry (case 1), MCCI occurs after RV failure. However, the integrity of the basemat can be maintained even with late CFS initiation. It was estimated that containment failure does not occur in either of these cases. Although the peak value of the hydrogen mole fraction exceeded the critical value on account of the MCCI, the oxygen mole fraction was too low and the steam mole fraction was too high to generate a hydrogen burn.
Accordingly, the source term was estimated only with the design leak. Among the 12 classes, the release fractions of those with Cs, tellurium, and CsI as representative isotopes were the highest (excluding the noble gases). Metallic fission products were additionally released by the gas transportation to the cavity when the RV fails, and the release fraction of these materials increased again, since the molten corium changed to light oxide in case 1. Although the release fractions of the metallic fission products were different, the overall source terms were similar in both cases because the release fractions of the metallic fission products are negligible compared to the release fractions of the noble gases, Cs, tellurium, and CsI. The Cs release fraction to the RRTs was about $25 \%$ in both cases.

Second, the source term according to the availability of the RRTs and the ACSS was estimated. For all cases, there 
was no containment failure because the pressures and hydrogen mole fractions were lower than the critical values. The release fraction of Cs to the environment increased more than two times from the base case when there was no water in the RRTs. However, the source term could be cut in half if the ACSS is available. Accordingly, the reduction effect that the RRT and the ACSS have on the release fraction was verified through the analysis results in Section 3.2.

The maximum release fraction of Cs to the environment was analyzed to be about $2.0 E-9$ when there is no water in the RRTs and the ACSS is unavailable. Based on this value, the maximum released activity of Cs-137 was calculated with the maximum core fission product inventories of SMART obtained from another study. The result was evaluated to be well below the regulatory limit of $100 \mathrm{TBq}$. As a result, this study verified that the SMART can maintain safety under the SBLOCA-induced severe accident condition. As further studies, estimation of the emergency planning zone and the radiation dose to the public based on the source term result found here can be conducted.

\section{Data Availability}

Data used to support this study are available from the corresponding author upon request.

\section{Conflicts of Interest}

The authors declare that they have no conflicts of interest.

\section{Acknowledgments}

This work was supported by a Korea Institute of Energy Technology Evaluation and Planning (KETEP) granted financial resource from the Ministry of Trade, Industry and Energy, Republic of Korea (no. 20193110100090).

\section{References}

[1] H. B. Delmastro, M. Markiewicz, E. Lopasso et al., "CAREM project status," Science and Technology of Nuclear Installations, vol. 2011, p. 1, Article ID 140373, 2011.

[2] World Nuclear Association Website, Small Nuclear Power Reactors, World Nuclear Association Website, London, UK, 2020, https://www.world-nuclear.org/information-library/ nuclear-fuel-cycle/nuclear-power-reactors/small-nuclear-powerreactors.aspx.

[3] D. T. Ingersoll, Z. J. Houghton, R. Bromm, and C. Desportes, "NuScale small modular reactor for co-generation of electricity and water," Desalination, vol. 340, pp. 84-93, 2014.

[4] J. Ham, "Accident sequence analysis of a SBO in SMART100 using MELCOR," in Proceedings of the International Workshop on Post-Fukushima Challenges on Severe Accident Mitigation and Research Collaboration, Hotel INTERCITI, Daejeon, South Korea, November 2019.

[5] H. C. Kim, K. S. Ha, S. J. Kim et al., "Development of a Korean roadmap for technical issue resolution for fission product behavior during severe accidents," Nuclear Engineering and Technology, vol. 49, no. 8, pp. 1575-1588, 2017.

[6] K. Sunnevik, Comparison of MAAP and MELCOR and Evaluation of MELCOR as a Deterministic Tool within RASTEP, Uppsala Universitet, Uppsala, Sweden, 2014.
[7] SAND2017-0445O, MELCOR Computer Code Manuals, Vol. 1: Primer and Users' Guide, U.S. Nuclear Regulatory Commission, Rockville, MD, USA, 2018.

[8] SAND2017-0445O, MELCOR Computer Code Manuals, Vol. 2: Reference Manual, U.S. Nuclear Regulatory Commission, Rockville, MD, USA, 2018.

[9] NUREG/CR-4173, CORSOR User's Manual, U.S. Nuclear Regulatory Commission, Rockville, MD, USA, 1985.

[10] NUREG/CR-5765, SPARC-90: A Code for Calculating Fission Product Capture in Suppression Pools, U.S. Nuclear Regulatory Commission, Rockville, MD, USA, 1991.

[11] NUREG/CR-1391, MAEROS User Manual, U.S. Nuclear Regulatory Commission, Rockville, MD, USA, 1982.

[12] NUREG-1465, “Accident Source Terms for Light-Water Nuclear Power Plants," U.S. Nuclear Regulatory Commission, Rockville, MD, USA, 1995.

[13] SAND2013-6886J, MELCOR Simulations of the Severe Accident at Fukushima Unit 3, Sandia National Laboratories, Livermore, CA, USA, 2014.

[14] J. Ham, "Analysis on severe accident sequence in SMART100 using MELCOR," in Cooperative Severe Accident Research Program technical review Meeting and MELCOR Code Assessment Program Meeting, International Nuclear Information System, Vienna, Austria, August 2020. 